\title{
Covid-19 Community Mitigation Status at Selected Districts of Southwest Ethiopia: A Mixed Design Survey
}

\section{Serawit Lakew (D) $^{\prime}$ \\ Girma Gilano (D) ${ }^{2}$ \\ Tesfaye Feleke ${ }^{3}$}

'Maternal-Reproductive Health Nursing, College of Medicine and Health Sciences, Nech Sar Campus, Arba Minch University, Arba Minch, Southwest Ethiopia, Ethiopia; ${ }^{2} \mathrm{Health}$ Informatics, School of Public Health, College of Medicine and Health Sciences, Nech Sar Campus, Arba Minch University, Arba Minch, Southwest Ethiopia, Ethiopia; ${ }^{3}$ Health Education in School of Public Health, College of Medicine and Health Sciences, Nech Sar Campus, Arba Minch University, Arba Minch, Southwest Ethiopia, Ethiopia

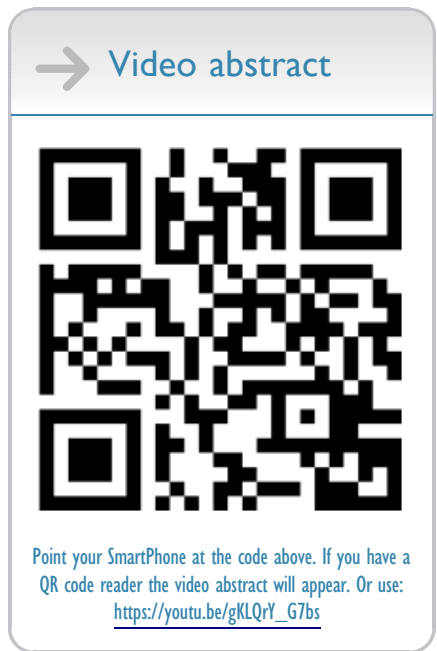

Correspondence: Serawit Lakew Maternal-Reproductive Health Nursing, College of Medicine and Health Sciences, Nech Sar Campus, Arba Minch University, Arba Minch, Southwest Ethiopia, Ethiopia $\mathrm{Tel}+251913273829$

Email Iserawit@yahoo.com
Background: The spread of covid-19 was alarmingly continued in Ethiopia. This survey assessed the status of community mitigations to fight the pandemic. The ongoing forward effort by local task forces can be assessed to note the achievements.

Methods: A mixed design using quantitative and qualitative triangulations used. Data was collected through interviewer administration using a structured W.H.O tool. The univariate and bivariate analysis employed to analyze descriptive statistics. The logistic regression model was applied to control confounders and determine potent predictors.

Objective: This study assessed community mitigation status on covid-19 pandemic at four selected districts of southwest Ethiopia: a mixed design survey.

Results: From the total of 624 participants interviewed, nearly half reported good mitigations toward fighting the covid-19 epidemic. This study suggested that nearly half (54.2\%) of the participants had good knowledge about the newly emerged epidemic symptoms. Three out of five participants had good Knowledge of preventive practices (63.1\%). Nearly four out of five $(72.6 \%)$ participants were knowledgeable about 14 days incubation period. The odds of having good mitigation to prevent covid-19 among the participants who had single marital status were $55 \%$ lower than those married union (AOR $=0.45,95 \% \mathrm{CI}: 0.24,0.86$ ). The odds of having good mitigation to prevent covid-19 among the participants (good knowledge symptoms) were 3.4 times higher than those with poor knowledge (AOR $=3.39,95 \% \mathrm{CI}$ : $2.19,5.23)$

Conclusions and Recommendations: Participants' mitigation status to fight covid-19 was promising. Handwashing with soap and water, disinfecting surfaces, and covering mouth or nose while coughing were mitigated practices by the vast majority. Home staying was the least mitigated practice. Participants' demographic status, knowledge of the epidemic symptoms, and knowledge of preventive measures were potent predictors of mitigations to fight covid-19. HID services should be extended to the rural population through HCWs and task forces.

Keywords: covid-19, mitigation, community, Gamo, Southwest Ethiopia

\section{Background}

The newly emerged coronavirus outbreak has created critical challenges for the general public health, research, and medical communities. Currently, the newest threat to global health is that the ongoing outbreak of respiratory disease that was recently given the name Coronavirus Disease 2019. Covid-19 was recognized in December $2019 .{ }^{1}$ It is shown to be caused by a completely unique coronavirus which is structurally associated with the virus that causes severe acute respiratory 
syndrome. It has occurred after the 2 preceding instances of emergence of coronavirus disease in the past 18 years, like SARS and MERS. ${ }^{2,3}$ Since its declaration of an epidemic in Wuhan-Hubei district of china, the new coronavirus quickly disseminated and infected around 103.9 million more global people and caused death to more than 2.26 million until 4 Feb 2021 report of WHO. ${ }^{4}$

CDCs, community mitigation are actions that persons and communities can take to help slow the transmission of the virus in communities. Its key concepts include 1.Slow transmission of disease and in particular to protect individuals at increased risk for severe illness, including older adults and persons of any age with underlying health conditions, and therefore the healthcare and important infrastructure workforces. 2. Emphasize individual responsibility, which has personal-level actions, empowering businesses, schools, and community organizations in order to implement recommended actions. Particularly, that protects persons at increased risk of severe illness, focusing on settings that provide critical infrastructure or services to individuals at increased risk of severe illness, and minimizing disruptions to lifestyle to the extent possible. 3. Tailor strategies to the target population. ${ }^{5}$

In China, a quick online cross-sectional survey showed that the correct answer rates of the 12 questions on the COVID-19 knowledge questionnaire were 70.2-98.6\%. The mean COVID-19 knowledge score was $10.8 \pm 1.6$ and overall $90 \%$ reported correct rate on the knowledge test. Knowledge scores significantly differed across genders, age-groups, categories of marital status, education levels, and residence places $(\mathrm{P}<0.001){ }^{6}$

In many countries and some communities, funerals were conducted in the homes of those who died; this was a key determinant of the Ebola outbreak. ${ }^{7}$ Given the role of body fluids in viral transmission and because of crowding during funerals in some settings, countries should establish new guidelines on funerals. Early risk communication strategies may help improve adherence among the population. $^{7,8}$

Several East African countries, including Ethiopia, have reacted quickly and decisively to curb the potential influx and spread of the coronavirus, very much in line with international guidelines. However, the report points out several factors which pose challenges to the containment and mitigation measures, in particular the large and densely populated urban informal settlements, poor access to safe water and sanitation facilities, and fragile health systems. Ultimately, the magnitude of the impact will depend on the public's reaction within respective countries, the spread of the disease, and the policy response. ${ }^{9}$

Ethiopia by 16 March 2020 responded to the pandemic through a two-week ban on mass gatherings, school closure, local transport, and border closure. Regional states had also taken strict measures to control the spread of the pandemic. This also includes community mitigation measures as tough as possible. ${ }^{10}$ So far, no study regarding community mitigations statuses to covid-19 pandemic exist in Ethiopia in general and study region in particular. This study, therefore, aimed to assess the community mitigations status at the southwestern of the Ethiopian region.

\section{Methods and Materials Study Design and Setting}

A community-based concurrent triangulation design was computed using separate quantitative and qualitative data collection tools and parallel data collection. The population total of the study area was 748,432 . The study districts include Arbaminch Zuria district $(223,336)$, Arbaminch town $(100,888)$, Bonke $(214,056)$, Daramalo $(109,186)$, and Mirab Abaya $(100,966) .{ }^{11}$

\section{A Conceptual Framework}

The socio-demographic factors like age, gender, marital status, educational status, occupational status, and permanent residential area of the participant could influence the proximate factors of the participant towards mitigation to the covid-19 pandemic. The information sources and Knowledge could in turn influence the community mitigation status of the covid-19 pandemic ${ }^{6,14-17}$ (Figure 1).

\section{Sample Size and Sampling Procedure}

For quantitative sampling, a multi-stage cluster sampling technique was employed to carry out the sampling. The four selected districts and Arbaminch town household number was 149,687 HHs. Among these, 634 representative households were selected randomly. Urban-rural stratification was done in each of the districts. For the cluster effect compensation, the design effect of 1.5 was considered. For this study, about $60 \%$ of the urban and rural kebele administrations (villages) were selected. Proportional allocation of the household offered to each study district and selected kebeles. A single person participant in the household was selected to participate in the survey randomly. Households were selected using a simple 


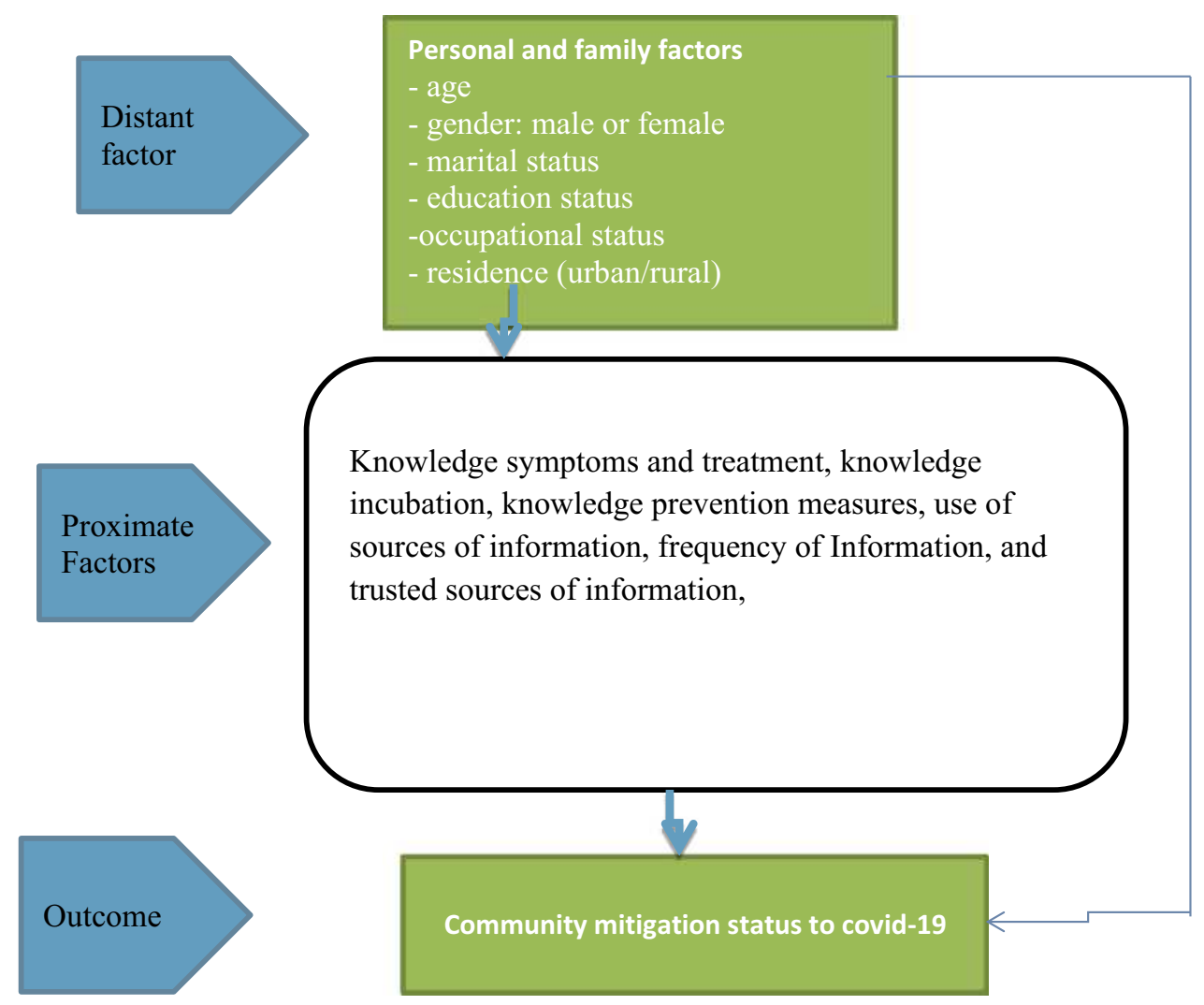

Figure I A conceptual framework that shows the relationship of community mitigation status towards covid-19 pandemic and its predictors. Note: Figure developed with data from references $6,14-17$, and 20 .

random sampling technique. Household list was obtained from kebele administrations of selected kebele (Figure 2).

For qualitative sampling: key informants were selected in the district based on their involvement in fighting the covid-19 pandemic. Selection criteria were any person who was a member of the task force at district, head of district administration, religious leader, or youth leader.

\section{Measurement}

For quantitative: data was collected using pretested and structured interviewer-administered questionnaire which consists of socio-demographic information, trust in sources of information, use of sources of information, frequency of information, risk group, knowledge symptoms and treatment, knowledge incubation, knowledge, and adherence to prevention measures, perceived preparedness, perceived self-efficacy and mitigation questions adopted from WHO survey tool ${ }^{18,19}$ with some modification to the local context. A five-point scale was used to score self-efficacy and preparedness. Mean score was used as a cut point to classify efficacy, preparedness, knowledge, and mitigations status as poor or good. For the mitigation, a "yes" response was considered as having mitigations of "good response". ODK application using a smartphone was used for data collection by enumerators. The questionnaire in ODK was prepared in English, Amharic, and Gamogna language options as per the best capability of respondent-interviewer communications. For qualitative: data was collected based on a pre-developed in-depth interview guide. It includes explorative questions on the status of mitigations, knowledge, trust, and sources of information for covid-19.

\section{Statistical Analysis}

For quantitative: The mean and proportions of the variables were computed by bivariate analysis and described in tables and graphs. A multivariate logistic regression model was employed to determine potent predictors. Based on this, first, a binary analysis was executed to find independent variables at p-value less than 0.25 . Then, candidate variables under the domains of independent factors were inserted into a multivariate logistic regression model for final adjustment. A P-value $<0.05$ was considered statistically significant in all comparisons. 


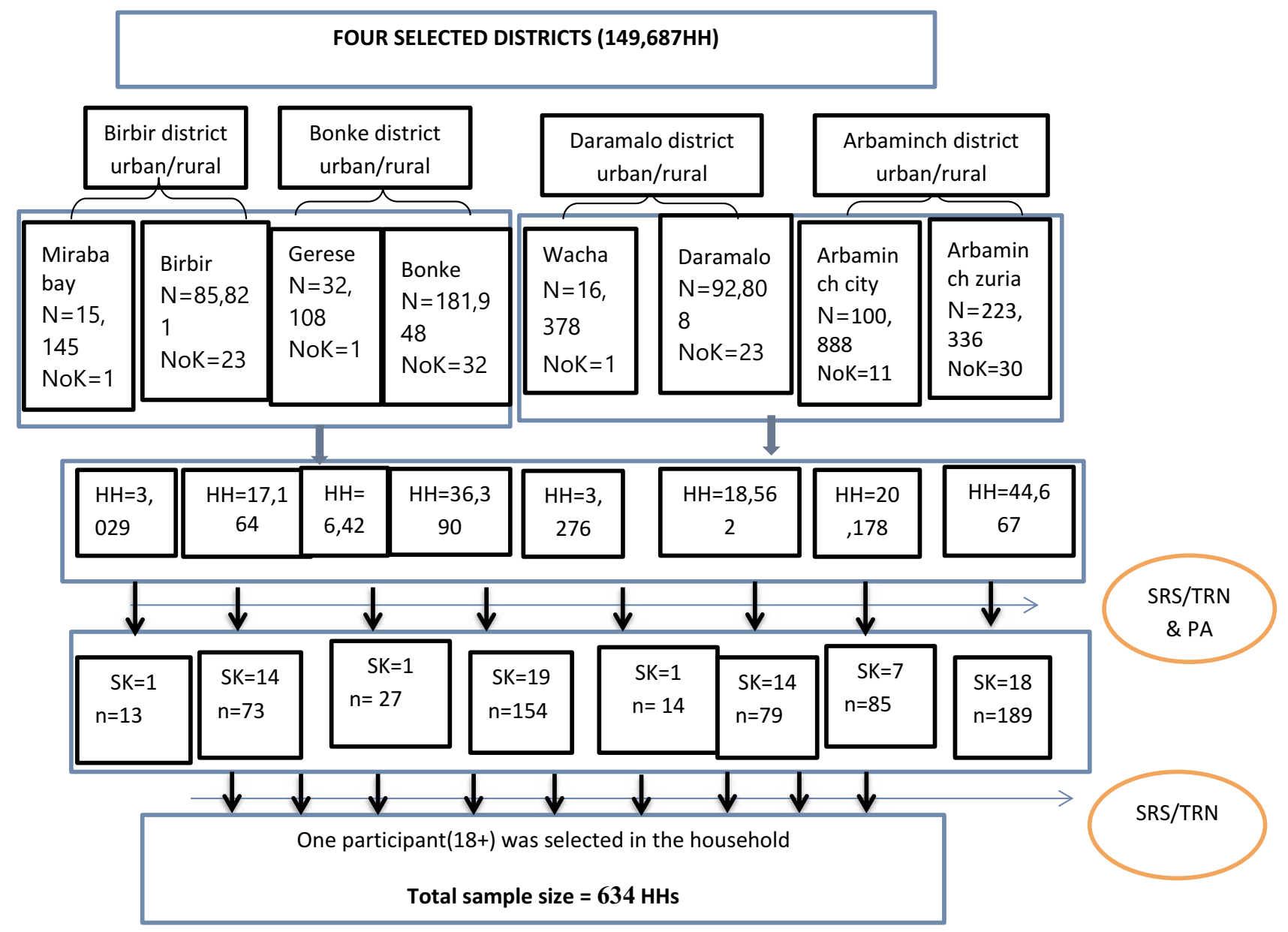

Figure 2 Sampling procedures and selection of representative participants in the study region.

Model fitness was checked by using the Hosmer and Lemeshow goodness fittest. Colinearity diagnosis was done using variance inflation factor (VIF) in STATA. Tool validity and reliability were checked at pre-testing time. For qualitative: Data was recorded upon collection from key informants by a mobile recorder. Recorded was transcribed by supervisors using thematizations. The result was concurrently placed with the result of quantitative in which quantitative first and then qualitative under each of the variables of interest.

\section{Data Quality Control}

The quality of data was assured by properly designing and pre-testing the questionnaire, proper training of the enumerators and supervisors for data collection using standard operating procedures (SOP) for quantitative and qualitative. The data collection tool was adopted from the WHO survey tool with some modifications to the local context. ${ }^{19}$ Every day, questionnaires were edited and checked for completeness before submission by supervisors and enumerators. Three data collection language options were used including local language.

\section{Ethical Issues}

The study was conducted following the 2013 revised Declaration of Helsinki and ethical clearance was obtained from the institutional review board (IRB) of Arbaminch University, College of Medicine and health sciences. Informed written consent was secured for each study subject and which is approved by IRB. Participants were communicated about the purpose, risk, and benefits of the study and were invited to participate. Confidentiality and privacy were kept utmost and all related queries were responded to for participation. Last, client protection was maintained through 2-meter social distancing between enumerator and respondent, hand hygiene, not handshaking the client, and using a mask by the enumerator and participant. 


\section{Results}

\section{Socio-Demographic Characteristics of the Study Participants}

Six hundred twenty-four (624) participants age 18 or more years participated in the study with a response rate of $98.4 \%$. The mean age of the participant ( \pm standard deviation) was $36.83 \pm 13.41$ years. Nearly two-thirds of the participant belongs to married union marital status (68.4\%) and High school and Elementary education completed (71.1\%). About ninety-eight percent (97.9\%) of the study participants were Christian religion followers where two-fold were Protestant Christians (66.0\%) and the remaining Orthodox $(31.9 \%)$. Close to two-thirds of the participants in the study area were from rural inhabitants (63.3\%). Table 1.

The mean \pm SD participant trusted sources of information reported were Government TV news $(3.65 \pm 1.0 \mathrm{SD})$, private TV news (3.37 \pm 1.1$)$, Conversation with friends and family (3.57 \pm 1.08$)$, Conversation with colleagues (3.54 \pm 1.1 ), consultation with Health care workers (4.48 \pm 0.74$)$, and Social media $(2.35 \pm 1.4)$. The mean \pm SD participant used sources of covid-19 information were Government TV news (3.92 \pm 1.05$)$, private TV news (3.58 \pm 1.19 ), Conversation with friends and family (3.61 \pm 1.14$)$,

Table I Socio-Demographic Characteristics of Study Participants $(n=624)$ at selected districts of Southwest Ethiopia, Gamo Zone Administrations, Ethiopia, from June to July 2020

\begin{tabular}{|l|l|l|l|}
\hline \multicolumn{2}{|l|}{ Socio-Demographic Variables } & Number & Percent \\
\hline Age in years & Less than 30 years & 267 & 42.8 \\
& $30-60$ years & 327 & 52.4 \\
& $60+$ & 30 & 4.8 \\
\hline Marital Status & Married Union & 427 & 68.4 \\
& Single & 150 & 24.0 \\
& Others* & 47 & 7.5 \\
\hline \multirow{2}{*}{ Gender } & Female & 231 & 37.0 \\
& Male & 393 & 63.0 \\
\hline \multirow{2}{*}{ Education } & Elementary & 332 & 53.2 \\
& High-school & 112 & 17.9 \\
& More High-school & 180 & 28.8 \\
\hline Religion & Protestant & 412 & 66.0 \\
& Orthodox & 199 & 31.9 \\
& Muslim & 13 & 2.1 \\
\hline Residence & Rural & 395 & 63.3 \\
& Urban & 229 & 36.7 \\
\hline
\end{tabular}

Note: Others*: widowed, divorced and separated marital status.
Conversation with colleagues $(3.6 \pm 1.15)$, consultation with Health care workers $(4.5 \pm 0.76)$, and Social media (2.56 \pm 1.55$)$. The most trusted (59.9\%) and used (61.4\%) information source was HCWs consultation. Very little trusted (39.6\%) and used (36.1\%) source of information was social media (such as Facebook, Twitter, Whatsapp). In the increasing order of a great deal of trust were social media (13.5\%), private TV news (18.9\%), conversation with family and friends $(23.2 \%)$, conversation with colleagues (24\%), government TV news (25\%) and consultation with health care workers (59.9\%) (Figures 3 and 4). KIs reported ....

Most trusted sources of information and used media sources by the community were in the first place government television news. Following were HCWs, HEWs, youths and task force, FMs, Radios, and Facebook in chronologic order.

Female 25 years rural KII: Major information sources to covid-19 symptoms, drugs/vaccine, mitigations, preventions, and other information are youth's task force HID in the village. The second is HCWs, excluding HEWs.

Male 28-64 years urban/rural KIIs: Most trusted Media are governmental television news, radios, FMs, Health care workers, and kebele task force authorities HIDs.

Facebook information is most common in the urban dwellers, the 28 years old urban KII reported.

The mean covid-19 knowledge symptoms score $( \pm \mathrm{SD})$ of the participant from 10 knowledge symptom questions was $6.3 \pm 2.6$. Participants who had scored mean and above knowledge score (Good knowledge symptoms) was $54.2 \%$. Majorly reported symptoms were headache (86.1\%) and cough $(86.9 \%)$. Low reported symptoms were diarrhea $(32.2 \%)$ and loss of smell taste $(41.3 \%)$ (Figure 5 and Table 2). The mean \pm SD knowledge score to preventive measures from 14 questions was $10.8 \pm 3.3$. Good knowledge preventive measures report was $63.1 \%$. Majorly reported knowledge preventive measures were hand hygiene $(91.3 \%)$, covering mouth while coughing/ sneezing (89.4\%), avoiding touching eyes/mouth/nose (88\%), wearing a face mask (86.7\%), and disinfecting surfaces (86.4\%). Disinfecting mobile phones (58.7\%) was the least reported preventive measure (Figure 6 and Table 2). The correct responses reported for knowledge of maximum covid-19 incubation period of 14 days was $72.6 \%$. About $70.8 \%$ of the participants were aware of having either no drug or vaccine to covid-19 during the study period (Table 2). 


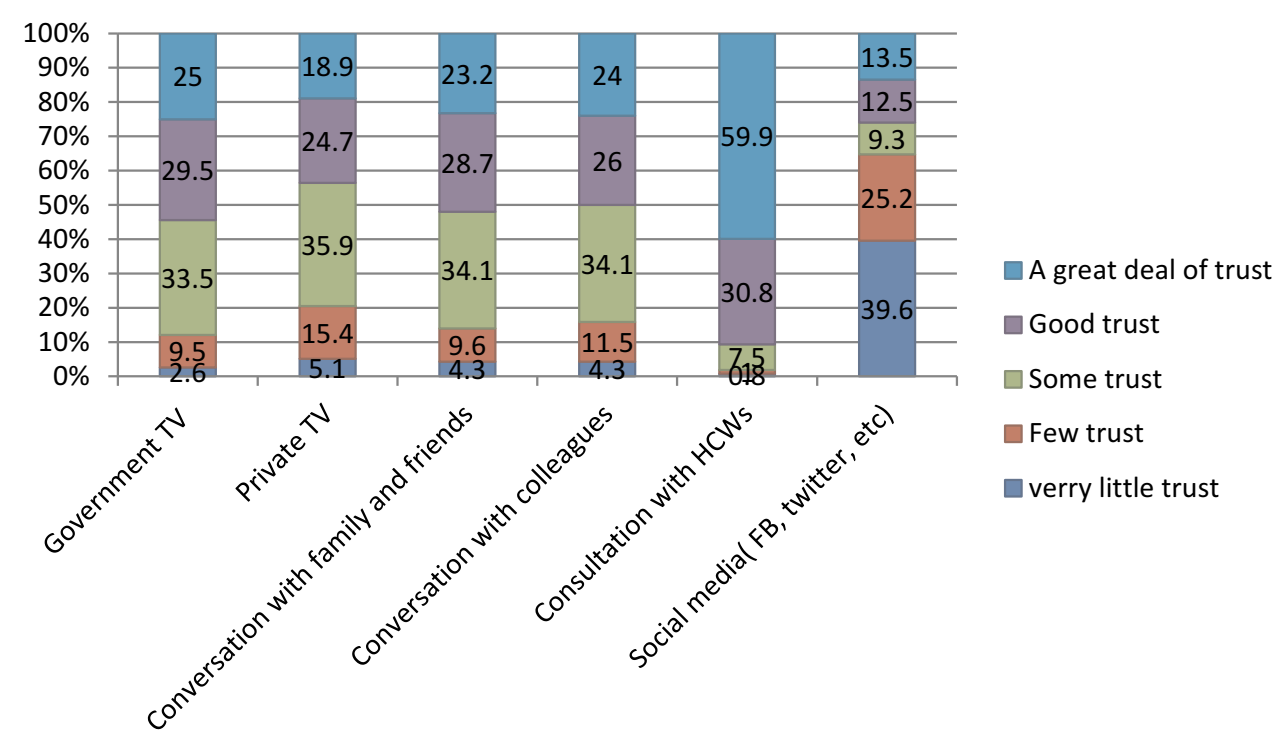

Figure 3 Percent distribution of participants trust in sources of covid-19 information in selected districts of Southwest Ethiopia, SNNPR, Gamo Zone, Ethiopia, June to July 2020 .

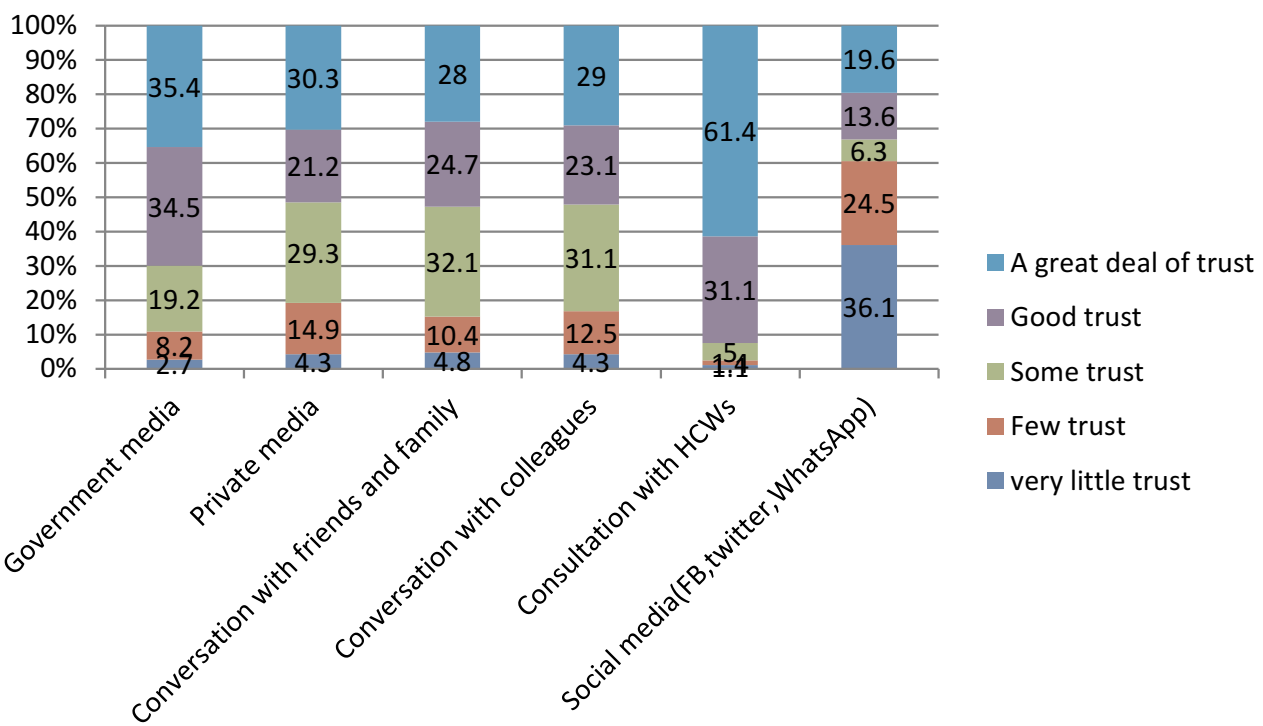

Figure 4 Percent distribution of participants uses of sources of covid-19 information in selected districts of Southwest Ethiopia, SNNPR, Gamo Zone, Ethiopia, June to July 2020.

The Key informants in qualitative reported that most urban inhabitants are relatively knowledgeable than rural for symptoms, availability of vaccine/drugs, and knowledge of self and family protection from coronavirus. Belief in human incapability to protect self is high among rural participants.

Male 28 years old urban KI: Most people do have adequate knowledge on symptoms, the existence of no treatment to covid-19, and how to be effectively protected from this pandemic.

Male 46 years old rural KI: Some educated are highly knowledgeable but uneducated farmers have knowledge symptoms gap until today. Most people say as there is no drug and vaccine to covid-19. Prevention knowledge involvement is very good except that they believe in incapability by human power. 


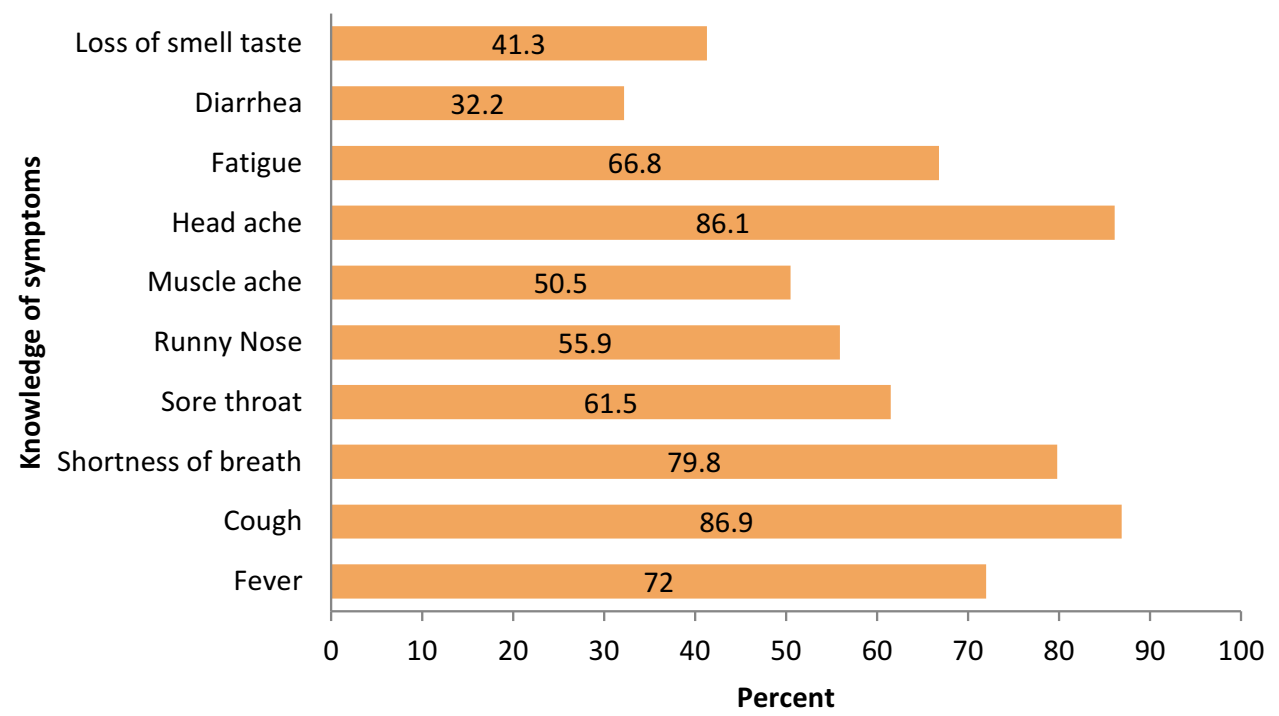

Figure 5 Percent distribution of participants based on knowledge of covid-19 symptoms in selected districts of southwest Ethiopia, SNNPR, Gamo Zone, Ethiopia, June to July 2020.

Male 64 years old urban KI: Difficult to say the majority is knowledgeable to corona symptoms. So, more information based on HID is needed. I am not sure whether people know about the treatment to covid-19. I guess most people know how to involve themselves in protection.

Male 29 years old rural KI: People know the symptoms such as cough. I guess, more than $75 \%$ know symptoms. For treatment, people do know as no treatment to covid-19 exists. For knowledge prevention, people are involved only as obeying authorities rather than practicing with a commitment for self-protection.

Male 29 years old urban KI: More half of the population is assumed to be knowledgeable regarding covid-19 symptoms and availability of treatment facility in the village and surroundings. They think as every causality dies immediately after the case is confirmed. Only a few knew preventive practices. They do practice only because others are involved in it.

Male 35 years old urban KI: More than half of our communities are hopefully aware of the pandemic, its symptoms, and prevention practices and treatment positively.

Woman 25 years old rural KI: Almost all people know as covid-19 has no drug and/or vaccine. But I do not think that our people know the symptoms of the episode. The symptom is, of course, fever and headache. People know how to protect it.

Table 2 Percent Distribution of Covid-19 Knowledge Miscellaneous of the Participants $(n=624)$ in selected districts of Southwest Ethiopia, SNNPR, Gamo Zone Administrations, Ethiopia, from June to July 2020

\begin{tabular}{|c|c|c|c|}
\hline Variables & Categories & Number & Percent \\
\hline \multirow[t]{2}{*}{ Covid-19 knowledge symptoms } & Good knowledge symptoms & 338 & 54.2 \\
\hline & Poor knowledge symptoms & 286 & 45.8 \\
\hline \multirow[t]{2}{*}{ Covid-19 knowledge preventive measures } & Good knowledge preventive measures & 394 & 63.1 \\
\hline & Poor knowledge preventive measures & 230 & 36.9 \\
\hline \multirow[t]{4}{*}{ Knowledge of maximum incubation period } & Up to 3 days & 24 & 3.8 \\
\hline & Up to seven days & 72 & 11.5 \\
\hline & Up to 14 days & 453 & 72.6 \\
\hline & Do not know & 75 & 12 \\
\hline \multirow[t]{2}{*}{ Knowledge of availability of drugs and/or vaccine } & Yes & 442 & 70.8 \\
\hline & No & 182 & 29.2 \\
\hline
\end{tabular}




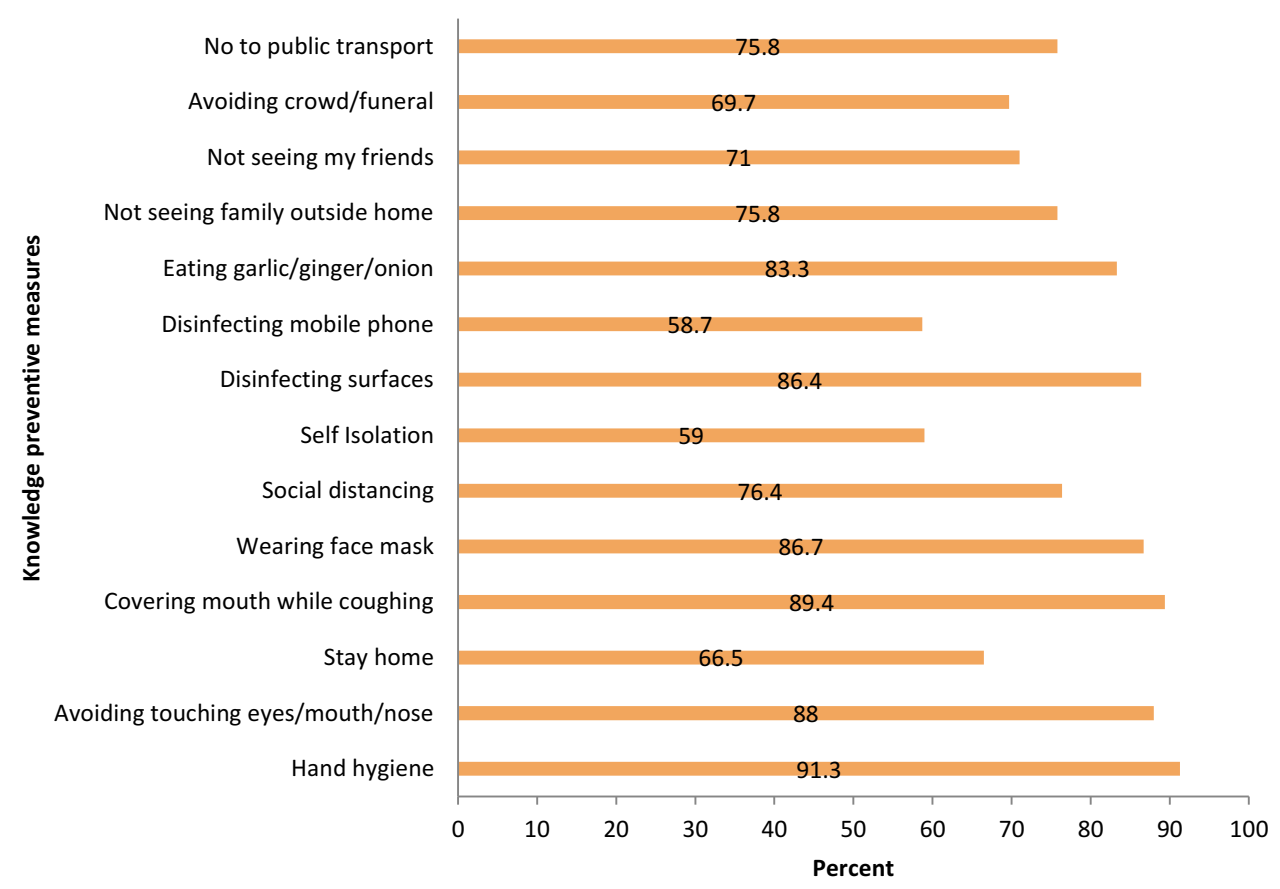

Figure 6 Percent distribution of participants based on knowledge of covid-19 preventive measures in selected districts of southwest Ethiopia, SNNPR, Gamo Zone, Ethiopia, June to July 2020.

Male 45 years old rural KI: Most people do not know the symptoms and treatment of covid-19. But, well know about how to protect themselves like hand hygiene, social distancing, homestay, and transport properly use or minimizing its use.

\section{Community Mitigations to Covid-19 Epidemic Response}

The mean mitigation status was $10.11 \pm 3.1$ SD. Mitigation statuses mean and above was 321 (51.4\%). Majorly reported mitigations were hand hygiene involvement 565 (90.5\%), disinfecting surfaces $568(91 \%)$, and covering mouth while coughing/sneezing $578(92.6 \%)$. About $85.3 \%$ of the participants were involved in eating garlic, ginger, and/or lemon during the epidemic. Below average participants mitigated for self-isolation $298(47.8 \%)$ and disinfecting the mobile phone 288 (46.2\%) (Table 3).

As can be summarized from the KIIs report, most population groups were well involved in the mitigations to fight corona back. Urban dwellers had better involvement over rural on Handwashing, alcohol hand rub use, social distancing, handshaking, homestay, avoiding worshipping in church, the existence of hand wash facility, aiding facility to poor's, and not increased use of alcohol. Funerals assembly involvement was poor in all study settings.
Nearly, quite half the society washes hands with soap and water. Hand wash facilities exist in the gateway of most urban study settings. Handwashing facilities are limited in the rural village and household gateways. Some hand wash was observed to fulfill the interest of the authorities than seeking benefit to them in rural. Many others are not washing properly. Only a few urban and rural dwellers use alcohol hand rub. Youth volunteers are strongly involved in the villages of both urban and rural. Homestay is not acceptable by nearly all in the rural setting except staying at own farmland for farmers. Mask use is only on a few both in urban and rural. Alcohol drink as covid-19 preventive does not exist in the majority except one rural district. Church visiting in the early time of episode was stopped in the urban districts for all types of worships. Rural churches in all had not closed from the beginning and continued yet without any precautions. Some urban churches closed and some others continued maintaining social distancing, minimized numbers of worshipers by the schedule in a day of Sabbath, and using hand wash facilitation at the gateway of the church. Orthodox Church worshippers are continued in both urban and rural settings with social distancing precautions but not seen closed yet. Some churches, such as Baptist and some protestant, make night time praying only. Garlic/ ginger/lemon use is prominent within the early time of 
Table 3 Percent Distribution of Covid-19 Community Mitigation Response of the Participants ( $\mathrm{n}=624)$ in selected districts of Southwest Ethiopia, SNNPR, Gamo Zone Administrations, Ethiopia, June to July 2020

\begin{tabular}{|c|c|c|c|}
\hline \multirow[t]{2}{*}{ Variables } & \multicolumn{3}{|c|}{ Categories, Number (\%) } \\
\hline & Yes & No & Do Not Apply \\
\hline Hand washing for at least 20 seconds or alcohol hand rub & $565(90.5)$ & $55(8.8)$ & $4(0.6)$ \\
\hline Avoiding touching your eyes, nose, and mouth with unwashed hands & $517(82.9)$ & $103(16.5)$ & $4(0.6)$ \\
\hline Staying home when you were sick or when you had a cold & $368(59)$ & $24 I(38.6)$ & $15(2.4)$ \\
\hline Covering your mouth and nose when you cough or sneeze & $578(92.6)$ & $44(7.1)$ & $2(0.3)$ \\
\hline Wearing a face mask & $480(76.9)$ & $|4|(22.6)$ & $3(0.5)$ \\
\hline Physical distancing (keeping minimum $2 \mathrm{~m}$ ) & $490(78.5)$ & $130(20.8)$ & $4(0.6)$ \\
\hline Self-isolation & 298(47.8) & $313(50.2)$ & $13(2.1)$ \\
\hline Disinfecting surfaces & $568(91)$ & $53(8.5)$ & $3(0.5)$ \\
\hline Disinfecting the mobile phone & $288(46.2)$ & $270(43.3)$ & $66(10.6)$ \\
\hline Eating garlic, ginger, lemon & $532(85.3)$ & $86(13.8)$ & $6(1.0)$ \\
\hline Not seeing my family living outside my own home & $417(66.8)$ & $200(32.1)$ & $7(1.1)$ \\
\hline Not seeing my friends & $391(62.7)$ & $225(36.1)$ & $8(1.3)$ \\
\hline Not gone to any crowded place (faith, funeral.) & $36 \mid(57.9)$ & $254(40.7)$ & $9(1.4)$ \\
\hline Not used public transport to travel & $456(73.1)$ & $158(25.3)$ & $10(1.6)$ \\
\hline
\end{tabular}

pandemic in all study villages except a few. Funerals continued as usual in almost all villages. Aiding services are well going and offered to the poorest users as per the criteria at about three-fourths of the study villages. Hands shaking exist in the majority for rural and a few for urban dwellers. Physical exercise is seen in many deliberately and job-related. Eight male and female KIIs report between the ages of 25 to 64 .

\section{Association of Community Mitigation Status and Independent Predictors}

After Hosmer and Lemeshow's model adequacy was checked $(\mathrm{P}$-value $=0.48)$ the multivariate logistic regression model showed participants marital status; gender; covid-19 knowledge of symptoms; urban-rural residences; and covid-19 knowledge of preventive measures were potent predictors of community mitigation statuses. Age of the participant, gender, participant living with children, perceived preparedness, and perceived self-efficacy had an association with mitigation status only in binary logistic regression.
The odds of getting good mitigation to prevent covid19 among the participants who had single marital status were $55 \%$ less than those married union ( $\mathrm{AOR}=0.45,95 \%$ CI: $0.24,0.86$ ). Those categorized as others (widowed, separated, and divorced) were $60 \%$ less than married union marital status to have good mitigation $(\mathrm{AOR}=0.4$, 95\% CI: 0.17, 0.92). Odds of getting good mitigation to prevent covid-19 among the participants (urban place of residences) were 2 times above a rural place of residents $(\mathrm{AOR}=2.03,95 \% \mathrm{CI}: 1.15,3.56)$.

The odds of getting good mitigation to prevent covid19 among the participants (good knowledge of covid-19 symptoms) were 3.4 times higher than those with poor knowledge $(\mathrm{AOR}=3.39,95 \% \mathrm{CI}: 2.19,5.23)$. The chances of getting good mitigation to prevent covid-19 among the participants (good knowledge of preventive measures) were 21.6 times higher than those with poor knowledge prevention (AOR=21.61, 95\% CI: 12.95, 36.06) (Table 4).

\section{Discussion}

This community-based cross-sectional study attempted to assess the community mitigation status of the covid-19 
Table 4 Multivariable Logistic Regression Model to Identify Determinants of Community Mitigation Status Among Participants with Various Predictors in selected districts of Southwest Ethiopia, SNNPR $(n=624)$, Gamo Zone Administrations, Ethiopia, from June to July 2020

\begin{tabular}{|c|c|c|c|c|c|c|}
\hline \multicolumn{2}{|l|}{ Variables } & \multicolumn{2}{|c|}{$\begin{array}{l}\text { Community Mitigation } \\
\text { Status }\end{array}$} & \multirow[t]{2}{*}{$\operatorname{COR}(95 \% \mathrm{Cl})$} & \multirow[t]{2}{*}{$\operatorname{AOR}(95 \% \mathrm{Cl})$} & \multirow[t]{2}{*}{ p-value } \\
\hline & & $\begin{array}{l}\text { Poor, } \\
\text { n (\%) }\end{array}$ & $\begin{array}{l}\text { Good, } \\
\text { n (\%) }\end{array}$ & & & \\
\hline \multirow[t]{3}{*}{ Age (years) } & $<30$ & $158(52.1)$ & $109(34)$ & 1.00 & 1.00 & \\
\hline & $30-60$ & $138(45.5)$ & $189(58.9)$ & $1.98(1.43,2.76)^{*}$ & $\mathrm{I} .27(0.74,2.2 \mathrm{I})$ & $p>0.05$ \\
\hline & $>60$ & $7(2.3)$ & $23(7.2)$ & $4.76(1.97,11.5)^{*}$ & $2.58(0.74,8.94)$ & $P>0.05$ \\
\hline \multirow[t]{3}{*}{ Marital Status } & Married Union & $176(58.1)$ & $25 I(78.2)$ & 1.00 & 1.00 & \\
\hline & Single & $95(31.4)$ & $55(17.1)$ & $0.4 I(0.28,0.6)$ & $0.45(0.24,0.86)^{* *}$ & $P<0.01$ \\
\hline & Others $^{+}$ & $32(10.6)$ & $15(4.7)$ & $0.33(0.17,0.62)$ & $0.4(0.17,0.92)^{* *}$ & $P<0.05$ \\
\hline \multirow[t]{2}{*}{ Gender } & Female & $139(45.9)$ & $92(28.7)$ & 1.00 & 1.00 & \\
\hline & Male & $164(54.1)$ & $229(71.3)$ & $2.11(1.51,2.94)^{*}$ & $0.77(0.48, I .25)$ & $P>0.05$ \\
\hline \multirow{4}{*}{ Covid-19 knowledge of symptoms } & Poor & $183(60.4)$ & $103(32.1)$ & 1.00 & 1.00 & \\
\hline & knowledge & & & & & \\
\hline & Good & $120(39.6)$ & $218(67.9)$ & $3.23(2.32,4.48)$ & $3.39(2.19,5.23)^{* *}$ & $P<0.001$ \\
\hline & knowledge & & & & & \\
\hline \multirow[t]{3}{*}{$\begin{array}{l}\text { Covid- } 19 \text { knowledge of preventive } \\
\text { measures }\end{array}$} & $\begin{array}{l}\text { Poor } \\
\text { knowledge }\end{array}$ & & $30(9.3)$ & 1.00 & 1.00 & \\
\hline & Good & 103(34) & $291(90.7)$ & 18.83 & $21.61(12.95,36.06)$ & $P<0.001$ \\
\hline & knowledge & & & $(12.07,29.38)$ & $* *$ & \\
\hline \multirow[t]{2}{*}{ Perceived preparedness ${ }^{\$}$} & Not satisfying & $142(46.9)$ & $217(67.6)$ & 1.00 & 1.00 & \\
\hline & Satisfying & $16 \mid(53.1)$ & 104(39.2) & $0.42(0.3,0.58)^{*}$ & $0.59(0.34,01.02)$ & $p>0.05$ \\
\hline \multirow[t]{2}{*}{ Perceived self- efficacy ${ }^{\#}$} & Not satisfying & $99(32.7)$ & $124(38.6)$ & 1.00 & 1.00 & \\
\hline & Satisfying & $204(67.3)$ & $197(61.4)$ & $0.77(0.55,1.07)^{*}$ & $0.65(0.4,1.05)$ & $p>0.05$ \\
\hline \multirow[t]{2}{*}{ Place of Residence } & Rural & $182(60.1)$ & $213(66.4)$ & 1.00 & 1.00 & \\
\hline & Urban & $|2|(39.9)$ & $108(33.6)$ & $1.31(0.95,1.82)$ & $2.03(1.15,3.56)^{* *}$ & $P<0.01$ \\
\hline \multirow[t]{2}{*}{ Living with children } & No & $27(8.9)$ & $10(3.1)$ & 1.00 & 1.00 & \\
\hline & Yes & 276(9l.I) & $311(96.9)$ & $3.04(1.45,6.4)^{*}$ & $1.48(0.53,4.1 \mathrm{I})$ & $p>0.05$ \\
\hline
\end{tabular}

Notes: *Significant only in binary LR; **significant in binary and multivariate LR; ${ }^{+}$others includes married separated, divorced and widowed marital status; ${ }^{\$}$ self-belief towards capability to protect oneself; " belief on ability to be engaged in preventive action.

pandemic at Gamo zone, Southwest of Ethiopia. Findings showed respondents' mitigation status was related to demographics, knowledge, and residential area of the participants.

A mobile-based survey in 12 African countries (including sub-Saharan) suggested government efforts to minimize the spread of newly emerged disease emphasized behavioral interventions, including raising awareness of the disease and encouraging protective behaviors through community mitigations such as social distancing and Handwashing was most successful. ${ }^{20}$ This was in-line with this study that closer to half of the respondents had good mitigations toward fighting the covid-19 pandemic. It was still lowest than the Persian Gulf phone survey $(79.5 \%) .{ }^{21}$ Evidence showed that the Persian Gulf country (IRAN) had high earliest incidences of the epidemic than that of Ethiopia. ${ }^{22}$ Community involvement therefore could be increased due to increased awareness in Iran and vice versa in Ethiopia.

In China, the overwhelming majority of the participants had not visited any crowded place (96.4\%) and wore masks when going out $(98.0 \%)$ in recent days. ${ }^{6}$ But, only a coffee proportion of participants not gone to any crowded place and wore masks when going out of range in the present study. Rock bottom finding in Ethiopia might be associated with inclusions of rural populations who have not any internet 
access unlike that of Chinese. Regarding social distancing (61\%) and hand washing (84\%) involvement, nearly the very best was observed within the current study as compared to the previous Ethiopian Facebook survey. ${ }^{16}$ The KIs report could support this that ...

most population groups are well involved within the mitigations to fight corona back. Rural dwellers are poorly involved than urban for hand wash, alcohol hand rub use, social distancing, handshaking, homestay, worshipping in church, the existence of hand wash facility, aiding facility, and not increased use of alcohol. Funerals assembly involvement is poor altogether study settings.

This study suggested that almost half $(54.2 \%)$ of the participants had good knowledge about the newly emerged epidemic (covid-19) symptoms. Three out of five participants had good Knowledge of preventive practices (63.1\%). Nearly four out of five (72.6\%) participants were knowledgeable about 14 days incubation period. This was far and away low from chines recent online survey in overall knowledge survey (90\%), preventive practices (96.4-98\%) and vaccine/ drug availability awareness (94\%), ${ }^{6}$ and Tanzanian $(94.4 \%)^{17}$ and slightly less than Ethiopian Facebook online survey of knowledge prevention (78.8\%). ${ }^{16}$ The inconsistency altogether cases might be due to data collection technique differences in that they used a web survey whereas this study used face-to-face collection technique including rural non-internet user participants. This was because internet use might be associated with having high information opportunities than non-use as evidence in the $\mathrm{USA}^{23}$. Qualitative KII also supported this that ...

People know the symptoms like cough. I guess, more than $75 \%$ know symptoms. For treatment, people do know as no treatment to covid-19 exists. For knowledge prevention, people involved only as obeying to authorities instead of practicing with commitment for self-protection ... 26 years old Male rural key informant.

Marital status (being re-married, cohabiting, separated, divorced, or widowed) was significantly related to having good mitigations to covid-19 epidemic response in one Chinese online internet-based survey. ${ }^{6}$ Contrarily, married status had a positive association with good mitigations within the current study. Increased family involvement might be associated with covid-19 interventions focused on women and family as recommended by the United Nations ${ }^{24}$ and global health guidelines so that it could have been vulnerable and marginalized groups in the fight against covid-19 in Ethiopia.
Having better knowledge of symptoms and preventive practices had positive implications for community-based mitigations to fight covid-19 as recent Ugandan and Chinese studies revealed. ${ }^{6,14}$ It was supplemented by this study in that participants who had Good knowledge symptoms and knowledge preventive measures were about three times and twenty-two times more likely to mitigate for covid-19 response than their counterparts, respectively. Being aware of could probably lead to a positive behavior for protection as human being naturally seeks safety and healthy life.

As revealed in an online phone interview survey in all nine Ethiopian regions and a Chinese online internet survey, being a rural resident was an independent risky predictor of community mitigations to respond to covid-19 epidemics. ${ }^{6,15}$ This was supported by this study in that urban dwellers were two times more likely to mitigate than rural. Increased access to information could be blamed for the variability in which urban dwellers might have a better opportunity than rural. New York pocket study also confirmed the justifications. The majority of Key Informants also reported that

\begin{abstract}
... most urban inhabitants are relatively knowledgeable than rural for symptoms, availability of vaccine/drugs and knowledge of self and family protection of coronavirus. Most urban population groups are well involved in the mitigations to fight corona back than rural. When specifically seen, urban participants had involved on hand wash, alcohol hand rub use, social distancing, handshaking, homestay, worshipping in church, the existence of hand wash facility, aiding facility, and not increased use of alcohol better than rural.
\end{abstract}

\section{Strengths of the Study}

Being community-based is an advantage for better representing the study region on the outcome variable. This was because it included respondents of various cultures, living status, education, urban/rural inclusion, and employment. Being triangulated design was also the strength where findings were supporting each other. Moreover, being a face-to-face interview data collection technique used was an advantage for all-inclusive data access over being an internet-based online survey.

\section{Limitations of the Study}

Design-related cause-effect relationships for all significant associations might have affected the data. Social desirability bias could have a little bit affected the quality of data because study subjects might get difficulty answering malpractices in 
the presence of an interviewer. This bias was minimized via interviewing with privacy, confidentiality assurances, and prior information about the aim and benefits of the study. An interview quality to some extent may be affected because of fear of transmission of the infection to the interviewer though efforts had been made to minimize bias via using masks, alcohol hand rub, and maintaining adequate social distancing between the study subject and interviewer.

\section{Conclusions and Recommendations}

Participants' mitigation status to fight covid-19 was promising. Handwashing with soap and water, disinfecting surfaces, and covering mouth or nose while coughing was mitigated practices by the vast majority. Home staying was the least mitigated practice. The vast majority of the participants ( 9 out of 10) were involved in eating ginger, garlic, and/or lemon with the hope that it kills if being infected. Huge numbers of participants (more than 7 out of ten) were generally knowledgeable about major symptoms (cough, fever and headache), prevention practices, and availability of drugs (vaccine) to covid-19. Participants' demographic status, knowledge of the epidemic symptoms, knowledge of preventive measures, and place of residence were potent predictors of mitigations to fight covid-19. Increased multisectoral and religious involvement in the task forces should be considered. HID services should be continued to the rural population through HCWs and task force efforts. Marginalized and vulnerable groups should be focused and involved.

\section{Abbreviations}

CDC, Center for Diseases Prevention and Control; HCW, Health Care Workers; HID, Health Information Dissemination; KII, Key Informant Interview; ODK, Open data Kit; MERS, Middle East Respiratory Syndrome; WHO, World Health Organization; SNNPR, Southern National Nationalities and Peoples Regional State.

\section{Acknowledgments}

Our special gratitude and appreciation goes to the Arbaminch University covid-19 special committee for funding data collection of this research project. We were also grateful to Gamo Zone administrators, District Health Bureau, village administrators, respondents and supervisors for their unreserved effort to the success of this work.

\section{Author Contributions}

All authors made a significant contribution to the work reported, whether that is in the conception, study design, execution, acquisition of data, analysis and interpretation, or in all these areas; took part in drafting, revising or critically reviewing the article; gave final approval of the version to be published; have agreed on the journal to which the article has been submitted; and agree to be accountable for all aspects of the work.

\section{Disclosure}

The authors report no conflicts of interest for this work.

\section{References}

1. World Health Organization. Pneumonia of unknown cause - China: disease outbreak news. Geneva: World Health Organization. Available from: https://www.who.int/csr/don/05-january-2020pneumonia-of-unkown-cause-china/en/. Accessed January 5, 2020.

2. World Health Organization. Coronavirus disease 2019 (COVID-19): situation report 44; 2020. Available from: https://www.who.int/docs/ default-source/coronaviruse/situation-reports/20200304-sitrep-44covid-19.pdf?sfvrsn=783b4c9d_2. Accessed March 16, 2020.

3. Fauci AS, Lane HC, Redfield RR. Covid-19 - navigating the uncharted. $N$ Engl J Med. 2020;382:1268-1269. doi:10.1056/ NEJMe2002387

4. WHO (COVID-19) Homepage. WHO coronavirus disease (COVID-19) dashboard report. Available from: https://covid19.who. int/. Accessed February 4, 2021.

5. CDC. Coronavirus disease 2019 (COVID-19). Available from: https://www.cdc.gov/coronavirus/2019-ncov/php/open-america/com munity-mitigation.html. Accessed April 30, 2020.

6. Zhong B-L, Luo W, Li H-M, et al. Knowledge, attitudes, and practices towards COVID-19 among Chinese residents during the rapid rise period of the COVID-19 outbreak: a quick online cross-sectional survey. Int J Biol Sci. 2020;16(10):1745-1752. doi:10.7150/ijbs.45221

7. Pandey A, Atkins KE, Medlock J, et al. Strategies for containing Ebola in west Africa. Science. 2014;346:991-995. doi:10.1126/ science. 126061225414312

8. Ebrahim SH, Ahmed QA, Gozzer E, et al. Covid-19 and community mitigation strategies in a pandemic. BMJ. 2020;368:m1066. doi:10.1136/bmj.m1066

9. The World Bank. COVID-19 (Coronavirus) drives Sub-Saharan Africa toward first recession in 25 years. Available from: https:// www.worldbank.org/en/news/press-release/2020/04/09/covid-19coronavirus-drives-sub-saharan-africa. Accessed April 9, 2020.

10. Ethiopia: COVID-19 Humanitarian impact - Situation Update No. 01, As of 31 March 2020. OCHA; 2020. Available from: https://relief web.int/report/ethiopia/ethiopia-covid-19-humanitarian-impact-situa tion-update-no-01-31-march-2020.

11. Mengistua H. Gamo society vernacular house typologies and their science, Southern Ethiopia. Am Sci Res J Eng Technol Sci. 2013;3 (1):1-29.

12. Ssebuufu R, Sikakulya F, Binezero SM, et al. Awareness, knowledge, attitude and practice towards measures for prevention of the spread of COVID-19 in the Ugandans: a nationwide online cross-sectional Survey. Medrxiv. 2020. doi:10.1101/2020.05.05.20092247

13. Negera E, Demissie TM, Tafess K. Inadequate level of knowledge, mixed outlook and poor adherence to COVID-19 prevention guideline among Ethiopians. bioRxiv. 2020. doi:10.1101/2020.07.22.215590

14. Bekele D, Tolossa T, Tsegaye R, et al. The knowledge and practice towards COVID-19 pandemic prevention among residents of Ethiopia: an online cross-sectional study. PLoS One. 2021;16(1): e0234585. doi:10.1101/2020.06.01.127381 
15. Rugarabamu S, Ibrahim M, Byanaku A. Knowledge, attitudes, and practices (KAP) towards COVID-19: a quick online cross-sectional survey among Tanzanian residents. medRxiv. 2020. doi:10.1101/ 2020.04.26.20080820

16. World Health Organization. Q\&A on coronaviruses (COVID-19). 2020. Available from: https://www.who.int/news-room/q-a-detail/ q-a-coronaviruses. Accessed April 29, 2020.

17. WHO Regional Office for Europe. Survey tool and guidance rapid, simple, flexible behavioural insights on COVID-19 response; 2020. Available from: www.euro.who.int. Accessed May 2, 2020.

18. Food Security Group. Awareness, risk perceptions and safety behavior: how are men and women in Rural and Urban Africa Responding to COVID-19? Analysis of a recent mobile phone survey that looked at perceptions of the COVID-19 pandemic in 12 African countries. Michigan State University, Department of Agricultural, Food, and Resource Economics Food Security Group. 2020.

19. Paykani T, Zimet GD, Esmaeili R, et al. Perceived Social support and compliance with stay-at-home orders during the COVID-19 outbreak: evidence from Iran. BMC Public Health. 2020;20(1):1-9. doi:10.21203/ rs.3.rs-48105/v1
20. Paykani T, Zimet GD, Esmaeili R, Khajedaluee AR, Khajedaluee M. Perceived social support and compliance with stay-at-home orders during the COVID-19 outbreak: evidence from Iran. BMC Public Health. 2020;20:1650.

21. Li S, Feng B, Liao W, Pan W. Internet Use, Risk Awareness, and Demographic Characteristics Associated With Engagement in Preventive Behaviors and Testing: Cross-Sectional Survey on COVID-19 in the United States. J Med Internet Res. 2020;22(6):

22. United Nations policy brief: the impact of COVID-19 on women on April 9/2020 report. Available from: https://reliefweb.int/sites/relief web.int/files/resources/policy-brief-the-impact-of-covid-19-onwomen-en.pdf. Accessed March 16, 2021.

23. Marston C, Renedo A, Miles S. Community participation is crucial in a pandemic, prevention and control of non-communicable diseases in the COVID-19 response. Lancet. 2020;395. doi:10.1016/S0140-6736(20) 31067-9

24. Chen X, Orom H, Hay JL, et al. Differences in rural and urban health information access and use. J Rural Health. 2019;35(3):405-417. doi:10.1111/jrh. 12335
Risk Management and Healthcare Policy

\section{Publish your work in this journal}

Risk Management and Healthcare Policy is an international, peerreviewed, open access journal focusing on all aspects of public health, policy, and preventative measures to promote good health and improve morbidity and mortality in the population. The journal welcomes submitted papers covering original research, basic science, clinical \& epidemiological studies, reviews and evaluations,

\section{Dovepress}

guidelines, expert opinion and commentary, case reports and extended reports. The manuscript management system is completely online and includes a very quick and fair peer-review system, which is all easy to use. Visit http://www.dovepress.com/testimonials.php to read real quotes from published authors. 